\title{
THERMAL RADIATION AND MAGNETIC FIELD EFFECTS ON UNSTEADY MIXED CONVECTION FLOW AND MASS TRANSFER OVER A POROUS STRETCHING SURFACE WITH HEAT GENERATION
}

\author{
G.V.R. REDDY* \\ Department of Mathematics, KL University \\ Guntur, INDIA-522502 \\ E-mail: gvrr1976@klunivrsity.in \\ B.A. REDDY \\ Department of Mathematics, Fluid Dynamic Division \\ V.I.T, Vellore, (T.N), INDIA \\ N.B. REDDY \\ S.V. University \\ Tirupati, 517502. (A.P), INDIA
}

\begin{abstract}
The effects of thermal radiation and mass transfer on an unsteady hydromagnetic boundary layer mixed convection flow along a vertical porous stretching surface with heat generation are studied. The fluid is assumed to be viscous and incompressible. The governing partial differential equations are transformed into a system of ordinary differential equations using similarity variables. Numerical solutions of these equations are obtained by using the Runge-Kutta fourth order method along with the shooting technique. Velocity, temperature, concentration, the skin-friction coefficient, Nusselt number and Sherwood number for variations in the governing thermo physical parameters are computed, analyzed and discussed.
\end{abstract}

Key words: radiation, mass transfer, stretching surface, magnetic field, heat generation, temperature etc.

\section{Introduction}

The study of convective heat and mass transfer fluid flow over a stretching surface in the presence of thermal radiation, heat generation and chemical reaction is gaining a lot of attention. This study has many applications in industries and many engineering disciplines. These flows occur in many manufacturing processes in modern industry, such as hot rolling, hot extrusion, wire drawing and continuous casting. For example, in many metallurgical processes such as drawing of continuous filaments through quiescent fluids and annealing and tinning of copper wires, the properties of the end product depend greatly on the rate of cooling involved in these processes. Sakiadis (1961) was the first one to analyze the boundary layer flow on continuous surfaces. After that, Crane (1970) studied the boundary layer flow past a stretching plate. A few researchers considered the unsteady flows over a stretching surface. Wang (1990) studied an unsteady boundary layer flow of a finite liquid film by restricting the motion to a specified family of time dependence. Andersson et al. (1996) investigated the unsteady stretching flow in the case of power-law fluid film whereas Andersson et al. (2000) extended Wang's unsteady thin film stretching problem to the case of heat transfer. Recently, Ishak et al. (2009) presented the heat transfer characteristics caused by an unsteady stretching permeable surface with prescribed wall temperature. Sharidan et al. (2006) focused on a similarity analysis to investigate the unsteady boundary layer over a stretching sheet. Wang (2009) studied a viscous flow due to

\footnotetext{
* To whom correspondence should be addressed
} 
a stretching sheet with surface slip and suction. The thermal radiation and heat generation effects on an MHD convective flow is a new dimension added to the study of a stretching surface since it has important applications in physics and engineering, particularly, in space technology and high temperature processes. It plays an important role in controlling the heat transfer process in polymer processing industry. The effect of radiation on heat transfer problems was studied by Hossain and Takhar (1996), Takhar et al. (1996). Seddeek (2002) analyzed the effects of radiation and variable viscosity on a MHD free convection flow past a semiinfinite flat plate with an aligned magnetic field. In many chemical engineering processes, chemical reactions take place between a foreign mass and the working fluid which moves due to the stretch of a surface. Kandasamy et al. (2006) analyzed effects of chemical reaction, heat and mass transfer on a boundary layer flow over a porous wedge with heat radiation in the presence of suction or injection. Muhaimin et al. (2009) studied the effect of chemical reaction, heat and mass transfer on a nonlinear MHD boundary layer flow past a porous shrinking sheet with suction. Rajesh (2011) investigates chemical reaction and radiation effects on the transient MHD free convection flow of a dissipative fluid past an infinite vertical porous plate with ramped wall temperature.

In this paper, an attempt is made to investigate the effects of thermal radiation and magnetic field on an unsteady mixed convection flow and mass transfer over a vertical stretching surface in the presence of a heat source. The governing boundary layer equations are solved using the Runge-Kutta fourth order method along with the shooting technique. Velocity, temperature, concentration, skin-friction, the Nusselt number and Sherwood number for different values of thermo-physical parameters have been computed and the results are presented graphically and discussed qualitatively.

\section{Mathematical analysis}

We consider an unsteady two-dimensional mixed convection boundary layer flow of an incompressible viscous electrically conducting and radiating fluid over a vertical porous stretching surface moving with velocity $U_{w}(x, t)=\frac{c x}{1-\alpha t}$, where $c$ and $\alpha$ are constants and with temperature distribution $T_{w}=T_{\infty}+\frac{T_{0} c x}{2 v(1-\alpha t)^{2}}$ (Kandasamy et al., 2006), where $T_{0}$ is a reference temperature such that $0 \leq T_{0} \leq T_{w}$.

Here the stretching surface is subject to such amount of tension which does not alter the structure of the porous material. The $x$-axis is taken along the stretching surface in the direction of motion and the $y$-axis is perpendicular to it. A uniform magnetic field of strength $B_{0}$ is applied normal to the stretching surface. The magnetic Reynolds number is assumed to be small so that the induced magnetic field is negligible in comparison with the applied magnetic field. The fluid is assumed to be a gray, emitting and absorbing radiation, but non-scattering medium. The Rosseland approximation is used to describe the radiative heat flux in the energy equation. The radiative heat flux in the $x$-direction is considered negligible in comparison to the $y$ direction. It is assumed that the concentration of the diffusing species in the binary mixture is much smaller in comparison to the other chemical species, which are present, and hence the Soret and Dufour effects are negligible. It is also assumed that there is no chemical reaction between the diffusing species and the fluid.

Then under the above assumptions, in the absence of an input electric field, the governing boundary layer equations are

$$
\begin{aligned}
& \frac{\partial u}{\partial x}+\frac{\partial v}{\partial y}=0, \\
& \frac{\partial u}{\partial t}+u \frac{\partial u}{\partial x}+v \frac{\partial u}{\partial y}=v \frac{\partial^{2} u}{\partial y^{2}}+g \beta\left(T-T_{\infty}\right)+g \beta^{*}\left(C-C_{\infty}\right)-\frac{\sigma B_{0}^{2}}{\rho} u
\end{aligned}
$$




$$
\begin{aligned}
& \frac{\partial T}{\partial t}+u \frac{\partial T}{\partial x}+v \frac{\partial T}{\partial y}=\frac{k}{\rho c_{p}} \frac{\partial^{2} T}{\partial y^{2}}-\frac{1}{\rho c_{p}} \frac{\partial q_{r}}{\partial y}+\frac{Q_{0}}{\rho c_{p}}\left(T-T_{\infty}\right), \\
& \frac{\partial C}{\partial t}+u \frac{\partial C}{\partial x}+v \frac{\partial C}{\partial y}=D_{m} \frac{\partial^{2} C}{\partial y^{2}}
\end{aligned}
$$

The boundary conditions for the velocity, temperature and concentration fields are

$$
\begin{aligned}
& u=U_{w}, \quad v=V_{w}, \quad T=T_{w}, \quad C=C_{w} \quad \text { at } \quad y=0, \\
& u \rightarrow 0, \quad T \rightarrow T_{\infty}, \quad C \rightarrow C_{\infty} \quad \text { as } \quad y \rightarrow \infty
\end{aligned}
$$

where $u$ and $v$ are the velocity components along the $x$ and $y$-directions respectively, $t$ - the time, $V_{w}=-\sqrt{\frac{c v}{1-\alpha t}}$ - the velocity of the suction parameter $\left(V_{w}>0\right), v-$ the kinematics viscosity, $\beta$ - the volumetric coefficient of thermal expansion, $g$ - acceleration due to gravity, $B_{0}$ - the uniform magnetic field, $\sigma$ - the electrical conductivity, $c_{p}$ - the specific heat at constant pressure, $\rho$ - the density, $T$ - the temperature, $T_{\infty}$ - the temperature far away from the stretching surface, $k$ - the coefficient of thermal conductivity of the fluid, $Q_{0}$ - the heat generation constant and $q_{r}$ - the radiation heat flux.

By using the Rosseland approximation, the radiative heat flux is given by

$$
q_{r}=-\frac{4 \sigma_{s}}{3 k^{*}} \frac{\partial T^{4}}{\partial y}
$$

where $\sigma_{s}$ - the Stefan-Boltzman constant and $k^{*}$ - the absorption coefficient.

It should be noted that, by using the Rosseland approximation, the present analysis is limited to optically thick fluids. If the temperature differences within the flow field or sufficiently small, then Eq.(2.6) can be linearized by expanding $T^{4}$ into the Taylor's series about $T_{\infty}$, and neglecting higher order terms, we get

$$
T^{4}=4 T_{\infty}^{3} T-3 T_{\infty}^{4}
$$

Invoking Eqs (2.3), (2.6) and (2.7), it can be written as

$$
\frac{\partial T}{\partial t}+u \frac{\partial T}{\partial x}+v \frac{\partial T}{\partial y}=\left(\frac{k}{\rho c_{p}}+\frac{16 \sigma_{s} T_{\infty}^{3}}{3 \rho c_{p} k^{*}}\right) \frac{\partial^{2} T}{\partial y^{2}}+\frac{Q_{0}}{\rho c_{p}}\left(T-T_{\infty}\right) .
$$

The equation of continuity is satisfied if we choose a stream function $\psi(x, y)$ such that

$$
u=\frac{\partial \psi}{\partial y}, \quad v=-\frac{\partial \psi}{\partial x}
$$

We now introduce the similarity variable $\eta$ and the dimensionless variables $f$ and $\theta$ as follows 


$$
\begin{aligned}
& \eta=\sqrt{\frac{c}{v(1-\alpha t)}} y, \quad \psi(x, y)=\sqrt{\frac{c v}{(1-\alpha t)}} x f(\eta), \\
& \theta(\eta)=\frac{T-T_{\infty}}{T_{w}-T_{\infty}}, \quad Q=\frac{Q_{0} x}{\rho c_{p} U_{w}}, \\
& T=T_{\infty}+T_{0}\left[\frac{c x}{2 v(1-\alpha t)^{2}}\right] \theta(\eta), \\
& \phi(\eta)=\frac{C-C_{\infty}}{C_{w}-C_{\infty}}, \quad C=C_{\infty}+C_{0}\left[\frac{c x}{2 v(1-\alpha t)^{2}}\right] \phi(\eta) .
\end{aligned}
$$

In view of the above relations, the governing equations finally reduce to

$$
\begin{aligned}
& f^{\prime \prime \prime}+f f^{\prime \prime}-f^{\prime 2}-A\left(f^{\prime}+\frac{1}{2} \eta f^{\prime \prime}\right)-\lambda_{1} \theta-\lambda_{2} \phi-M f^{\prime}=0, \\
& \theta^{\prime \prime}+\frac{\operatorname{Pr}}{(1+R)}\left[f \theta^{\prime}-f^{\prime} \theta-\frac{A}{2}\left(\theta+\eta \theta^{\prime}\right)+Q \theta\right]=0, \\
& \phi^{\prime \prime}+\operatorname{Sc}\left[f \phi^{\prime}-f^{\prime} \phi-\frac{A}{2}\left(\phi+\eta \phi^{\prime}\right)\right]=0 .
\end{aligned}
$$

The corresponding boundary conditions are

$$
\begin{array}{lllll}
f=f_{0}, & f^{\prime}=1, & \theta=1, & \phi=1 & \text { at } \quad \eta=0, \\
f^{\prime} \rightarrow 0, & \theta \rightarrow 0, & \phi \rightarrow 0 & \text { as } & \eta \rightarrow \infty
\end{array}
$$

where $\operatorname{Pr}$ is the Prandtl number, $\lambda_{1}$ and $\lambda_{2}$ - the mixed convection parameters, $M$ - the magnetic parameter, Sc - the Schmidt number, $R$ - the thermal radiation parameter, $Q$ - the heat source parameter, $\alpha$ - the thermal diffusivity and $f_{0}=-V_{w} \sqrt{\frac{1-\alpha t}{c v}}, f_{0}>0$ corresponding to the suction parameter.

For this type of boundary layer flow, the skin-friction coefficient $\left(C_{f}\right)$, the local Nusselt number $(\mathrm{Nu})$ and Sherwood number (Sh) are important physical quantities.

Knowing the velocity field, the skin-friction at the stretching surface can be obtained, which in a non-dimensional form is given by

$$
C_{f}=\frac{2 \mu\left(\frac{\partial u}{\partial y}\right)_{y=0}}{\rho U_{w}^{2}} \Rightarrow \frac{1}{2} C_{f} \sqrt{\mathrm{Re}}=f^{\prime \prime}(0)
$$


where $\operatorname{Re}=\frac{u_{w}}{v}$ is the local Reynold's number.

Knowing the temperature field, the rate of heat transfer coefficient at the stretching surface can be obtained, which in a non-dimensional form, in terms of the Nusselt number, is given by

$$
\mathrm{Nu}=\frac{x\left(\frac{\partial T}{\partial y}\right)_{y=0}}{T_{w}-T_{\infty}} \Rightarrow \frac{\mathrm{Nu}}{\sqrt{\mathrm{Re}}}=-\theta^{\prime}(0) .
$$

Knowing the concentration field, the rate of mass transfer coefficient at the stretching surface can be obtained, which in a non-dimensional form, in terms of the Sherwood number, is given by

$$
\mathrm{Sh}=\frac{x\left(\frac{\partial C}{\partial y}\right)_{y=0}}{C_{w}-C_{\infty}} \Rightarrow \frac{\mathrm{Sh}}{\sqrt{\mathrm{Re}}}=-\phi^{\prime}(0) .
$$

\section{Solution of the problem}

The governing boundary layer Eqs (2.11) - (2.13) subject to boundary conditions (2.14) are solved numerically by using the Runge-Kutta fourth order method along with the shooting technique. First of all, higher order non-linear differential Eqs (2.11) - (2.13) are converted into simultaneous linear differential equations of first order and they are further transformed into the initial value problem by applying the shooting technique (Jain et al. [23]). The resultant initial value problem is solved by employing the RungeKutta fourth order technique. The step size $\Delta \eta=0.05$ is used o obtain the numerical solution with five decimal place accuracy as the criterion of convergence. From the process of numerical computation, the skin-friction coefficient, the Nusselt number and Sherwood number which are respectively proportional to $f^{\prime \prime}(0),-\theta^{\prime}(0)$ and $-\varphi^{\prime}(0)$ are also sorted out and their numerical values are presented in a tabular form.

\section{Results and discussion}

In order to get a physical insight into the problem, a representative set of numerical results is shown graphically in Figs 1-12, to illustrate the influence of physical parameters, viz., the suction parameter $f_{w}$, magnetic parameter $M$, mixed convection parameters $\lambda_{1}$ and $\lambda_{2}$ radiation parameter $R$, unsteadiness parameter $A$, heat generation $Q$, Prandtl number $\operatorname{Pr}$, and Schmidt number Sc on the velocity $f^{\prime}(\eta)$, temperature $\theta(\eta)$ and concentration $\varphi(\eta)$.

Figure 1 shows the dimensionless velocity profiles for different values of the magnetic parameter $M$. It can be seen that as $M$ increases, the velocity decreases. This result qualitatively agrees with the expectations, since the magnetic field exerts a retarding force on the flow. The effect of the unsteadiness parameter $A$ on the velocity field is shown in Fig.2. It is noticed that the velocity profiles decrease with the increase of the unsteadiness parameter $A$. It is interesting to note that the thickness of the boundary layer decreases with increasing values of $A$. The velocity profiles for different values of the suction parameter $f_{w}$ are illustrated in Fig.3. It is clear that increasing the values of $f_{w}$ results in a decreasing velocity. 


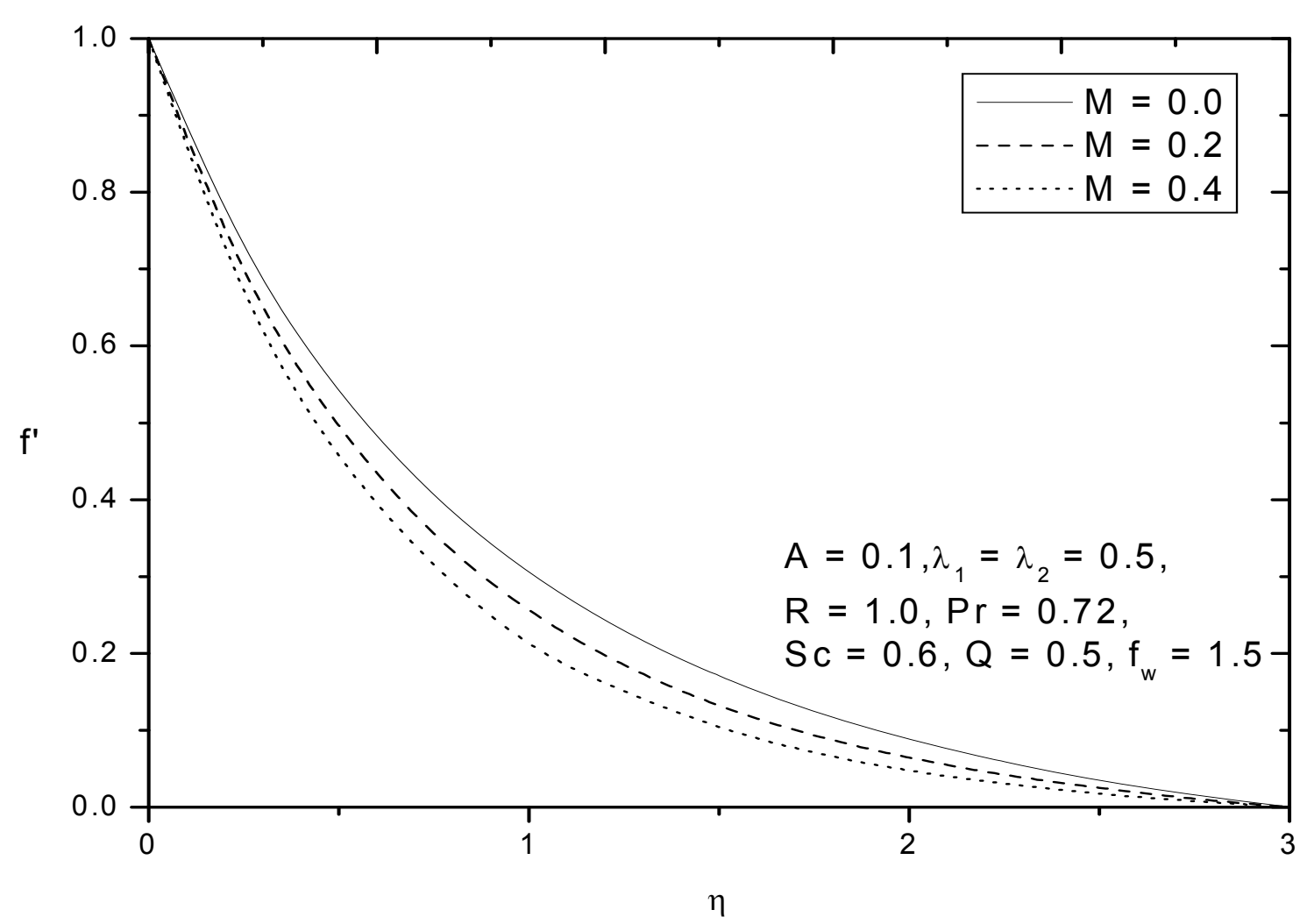

Fig.1. Velocity profiles for different values of $M$.

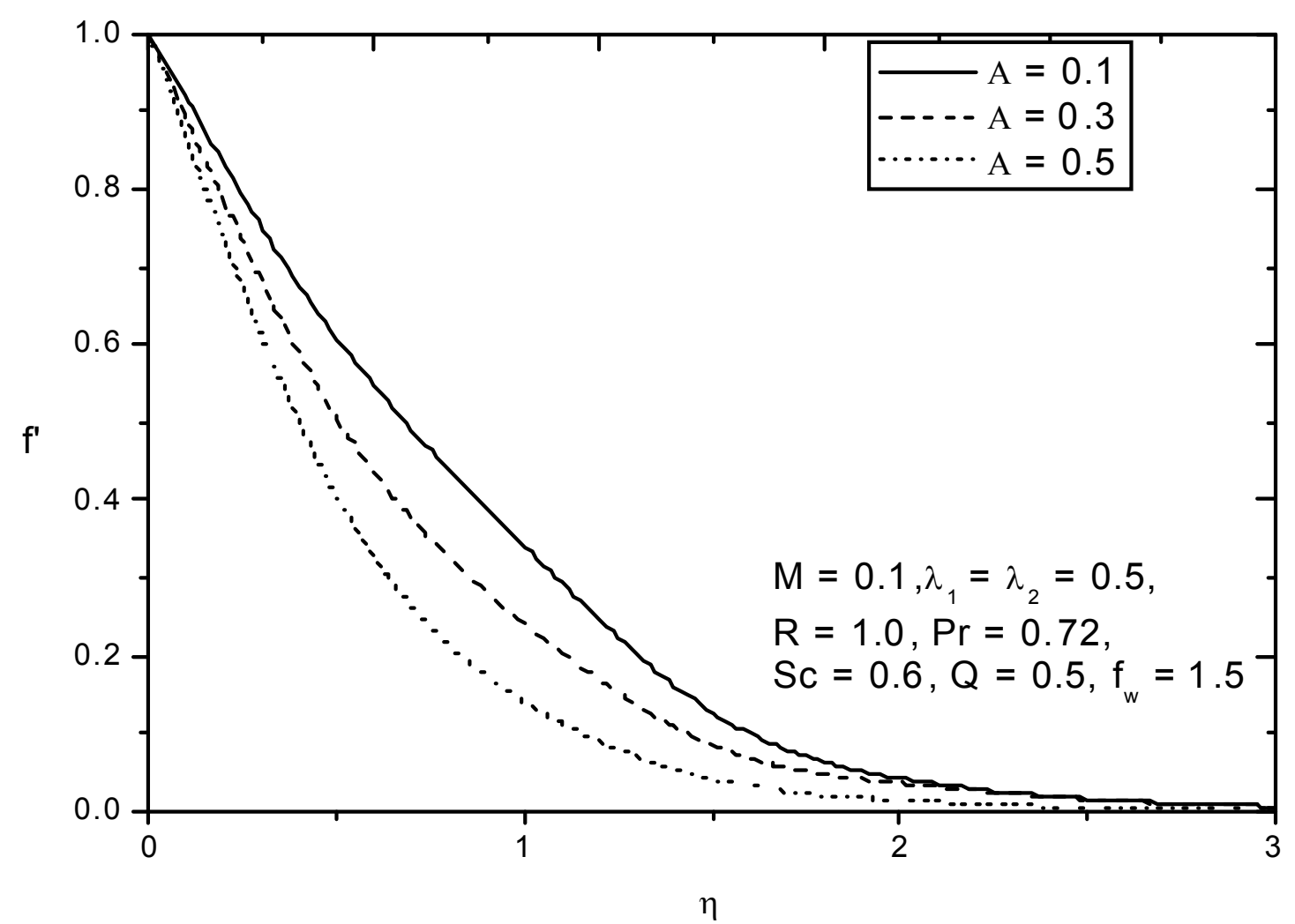

Fig.2. Velocity profiles for different values of $A$. 


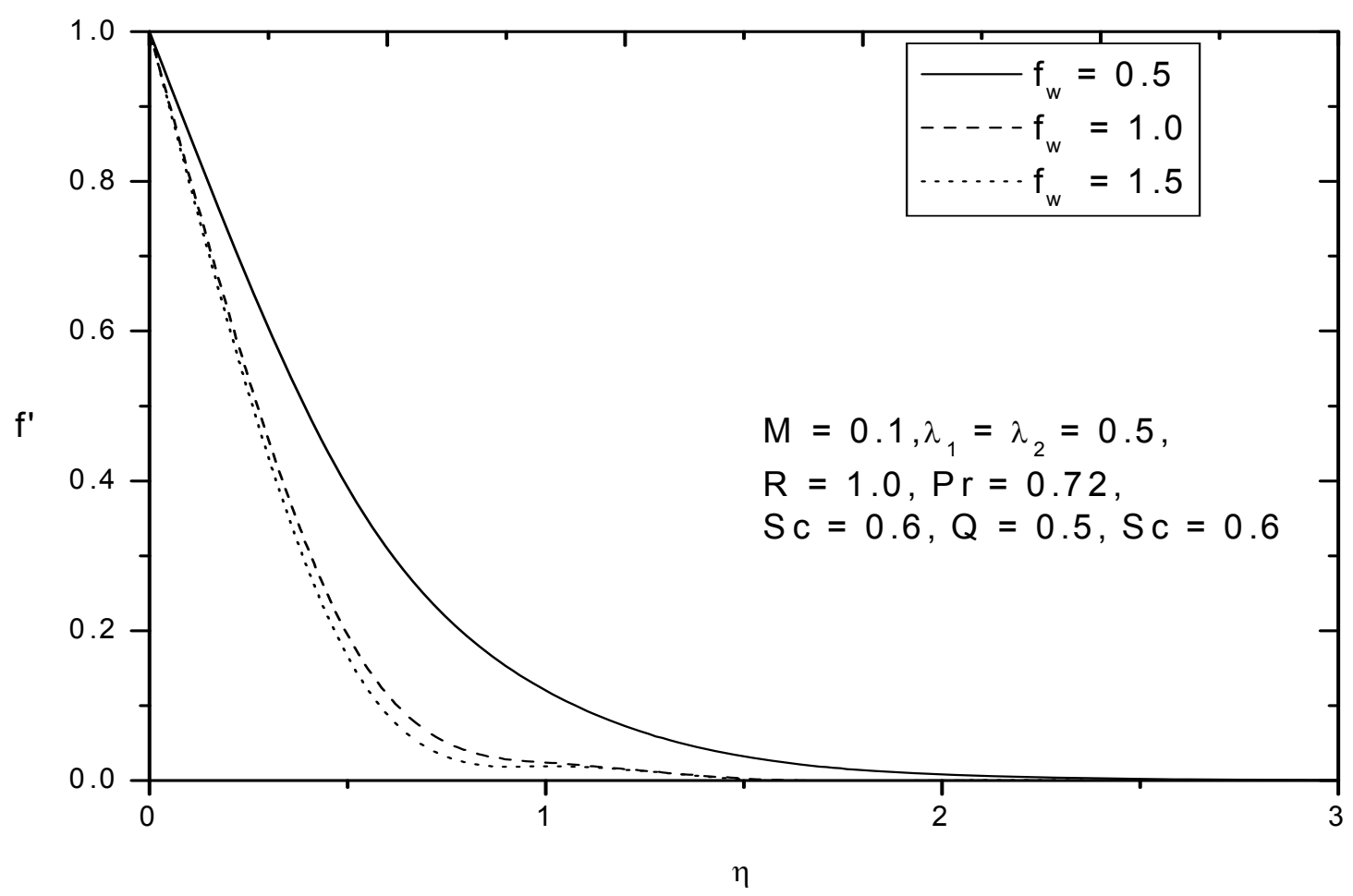

Fig.3. Velocity profiles for different values of $f_{w}$.

Figure 4 depicts the velocity profiles for different values of the mixed convection parameter $\lambda_{1}$. It is noticed that as the mixed convection parameter $\lambda_{2}$ increases, the velocity increases. A similar effect is observed for the case of the mixed convection parameter $\lambda_{2}$ which is not shown for brevity. The effect of the radiation parameter $R$ on the velocity profiles is shown in Fig.5. It is obvious that an increase in $R$ results in increasing the velocity within the boundary layer. The effect of heat source on the velocity field is shown Fig.6. It is noticed that under the constant magnetic field when the heat source parameter is increased the velocity of the fluid medium decreases. The effect of the magnetic parameter $M$ on the temperature profile is illustrated in Fig.7. It is clear that the temperature gradient at the surface decreases as the magnetic parameter increases. Figure 8 depicts the temperature profiles for different values of the suction parameter $f_{w .}$. It is noticed that as the suction parameter increases, the temperature decreases. The effect of the thermal radiation parameter $R$ on the temperature field is illustrated in Fig.9. It is observed that the temperature increases as the thermal radiation parameter $R$ increases. The effect of heat source parameter $Q$ on the temperature field is illustrated in Fig.10. It is observed that as $Q$ increases the temperature increases. The effect of the Prandtl number Pr on the temperature field is shown in Fig.11. It is observed that an increase in the Prandtl number contributes to a decrease in the temperature. The effect of the Schmidt number Sc on the concentration field is shown in Fig.12. It is observed that an increase in the Schmidt number contributes to a decrease in the temperature. 


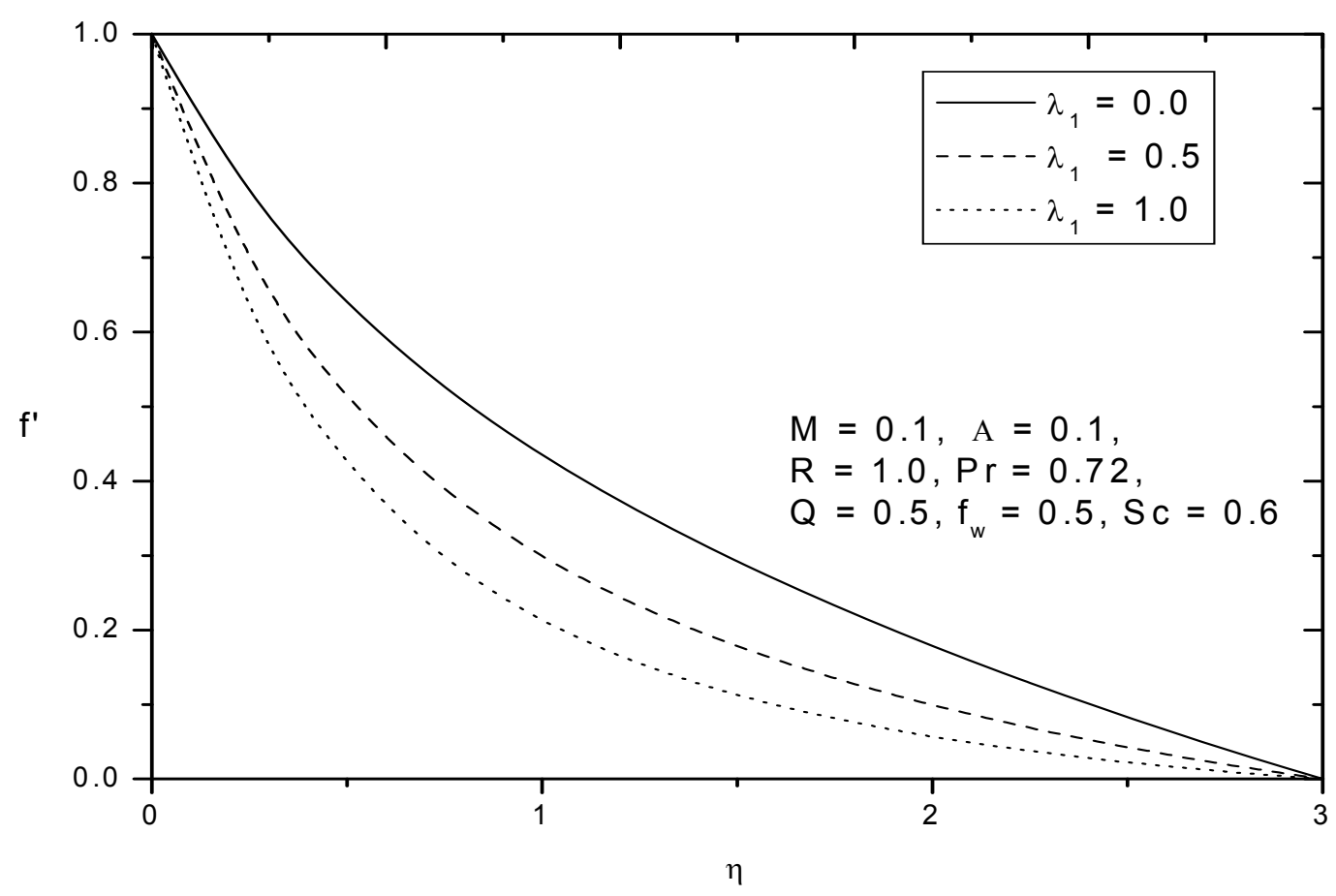

Fig.4. Velocity profiles for different values of $\lambda_{I}$.

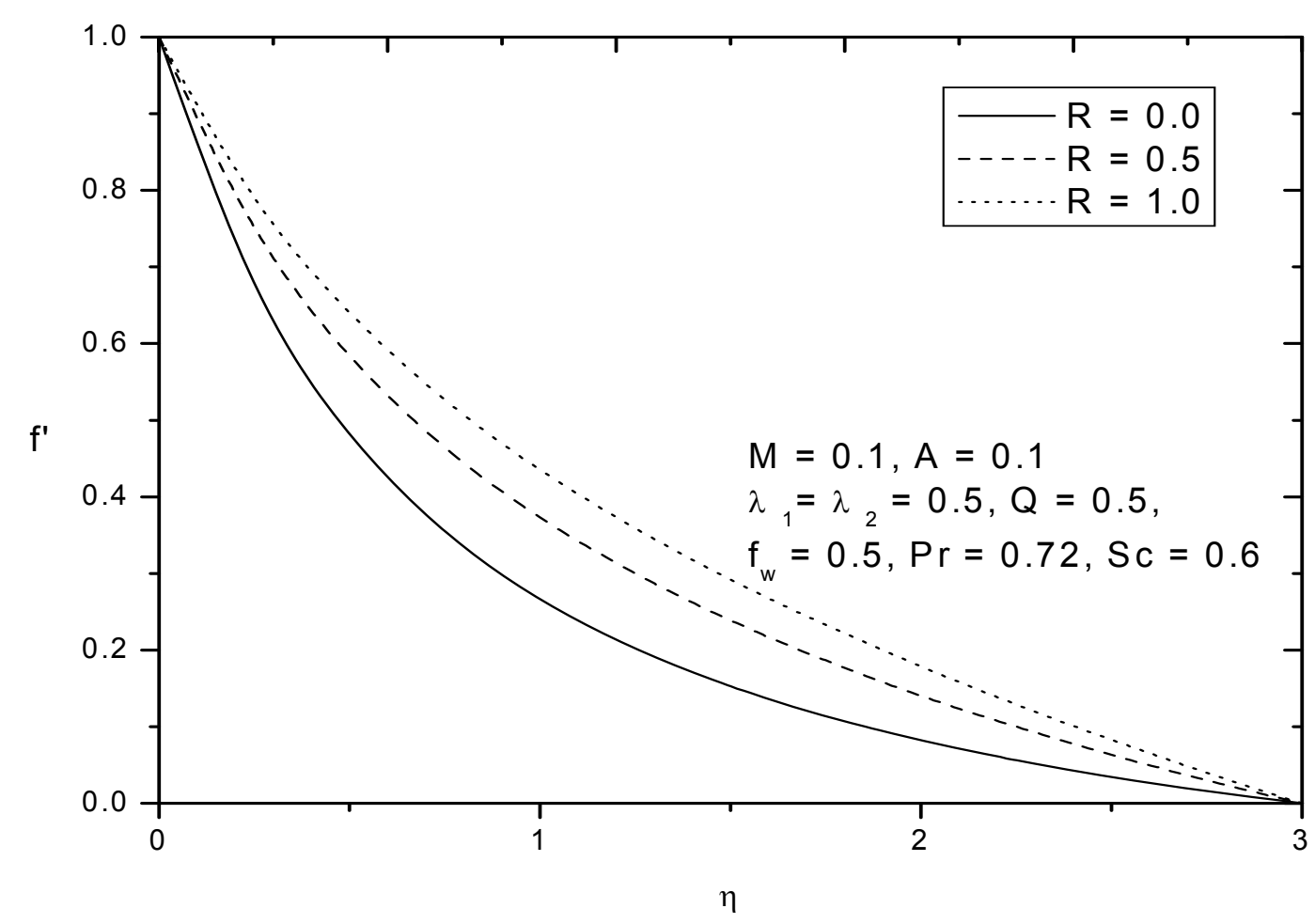

Fig.5. Velocity profiles for different values of $R$. 


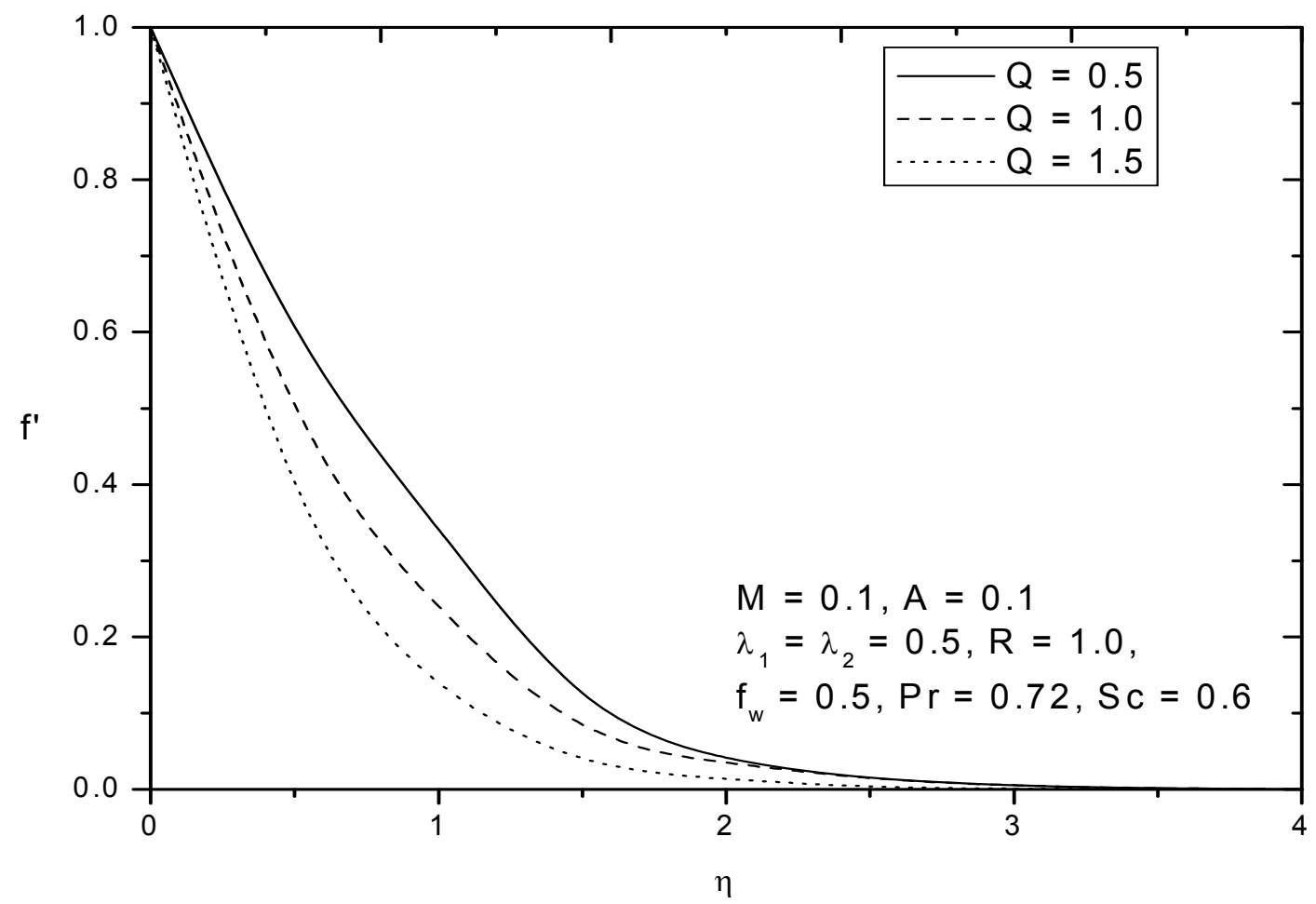

Fig.6. Velocity profiles for different values of $Q$.

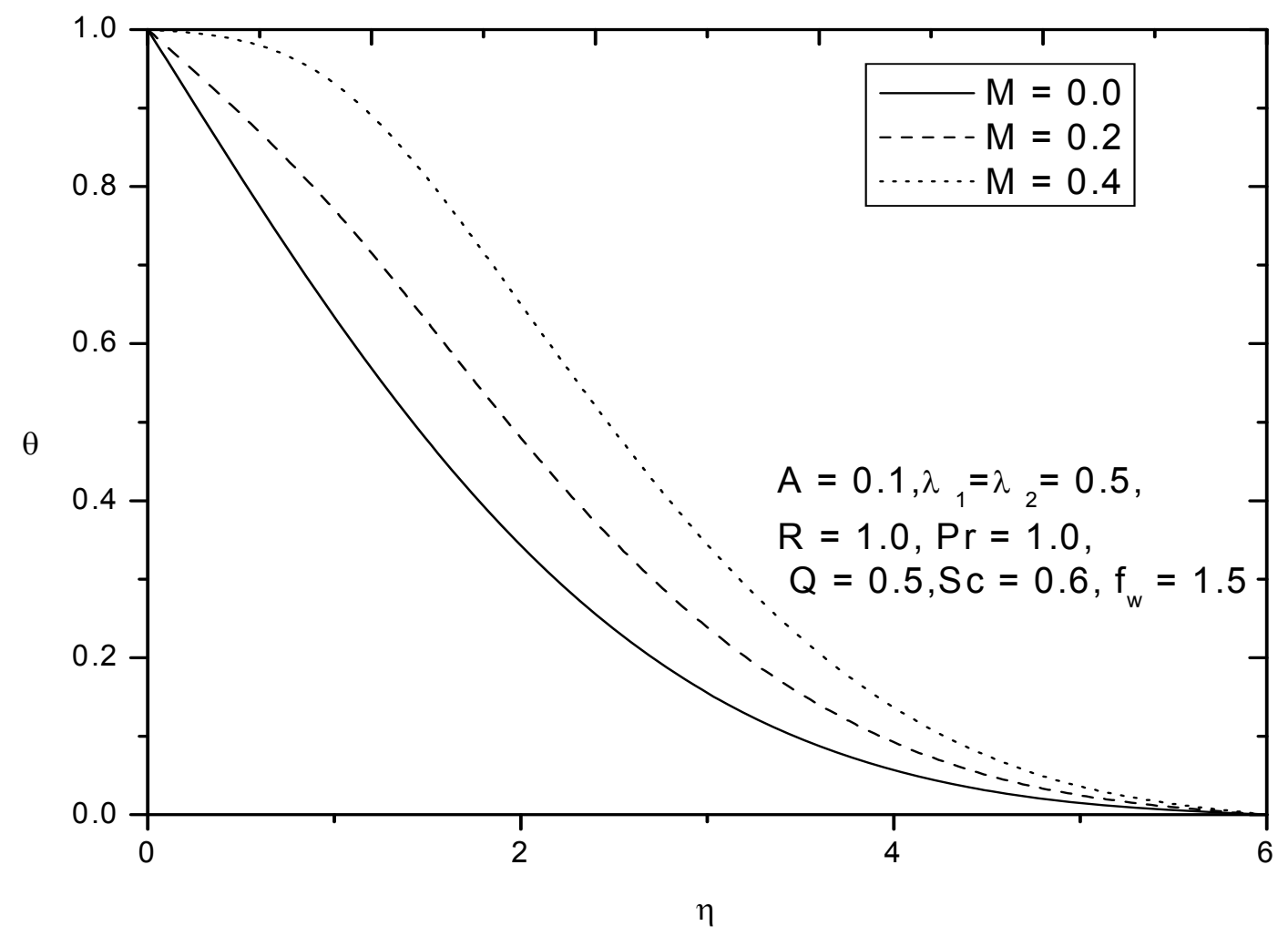

Fig.7. Temperature profiles for different values of $M$. 


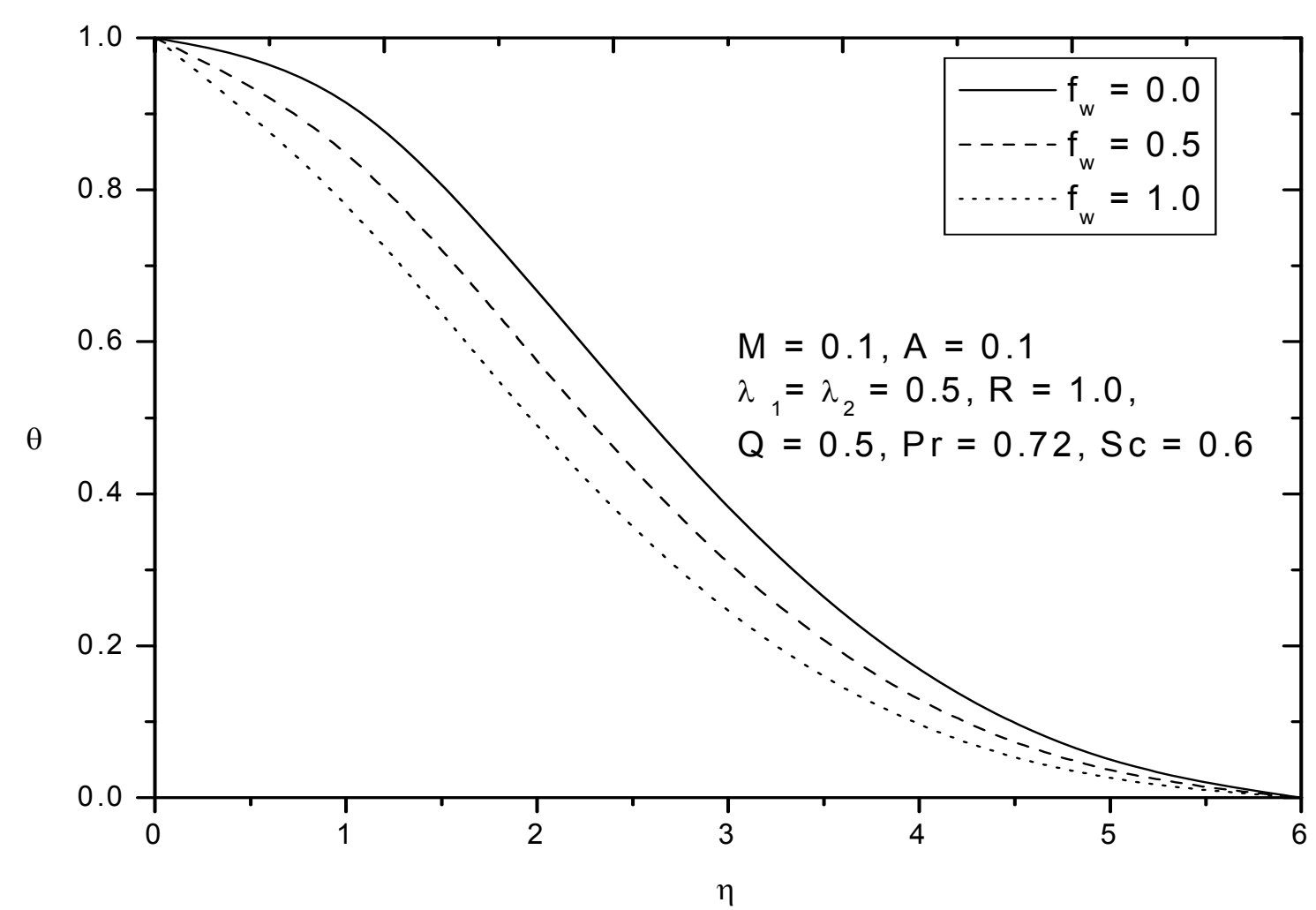

Fig.8. Temperature profiles for different values of $f_{w}$.

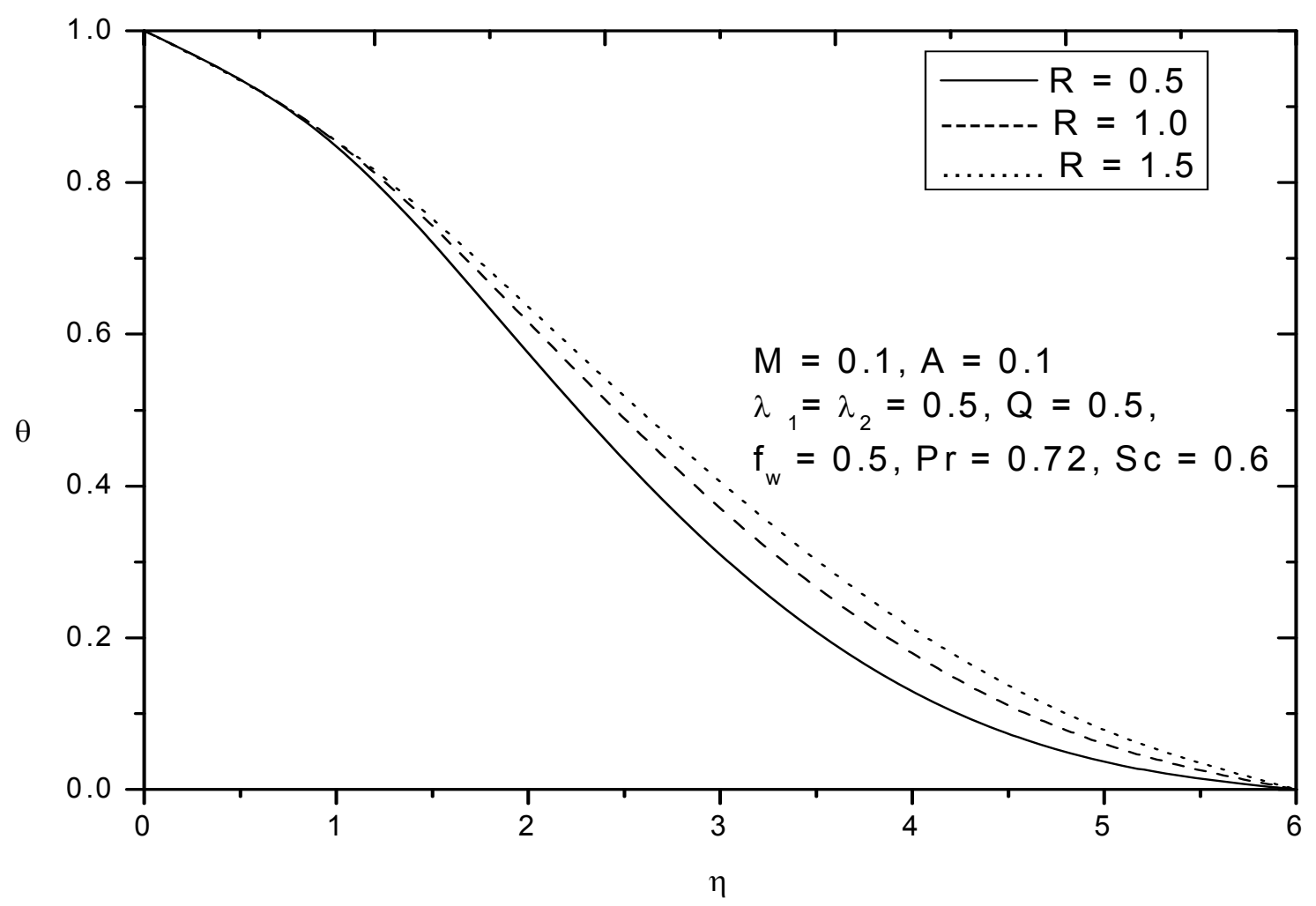

Fig.9. Temperature profiles for different values of $R$. 


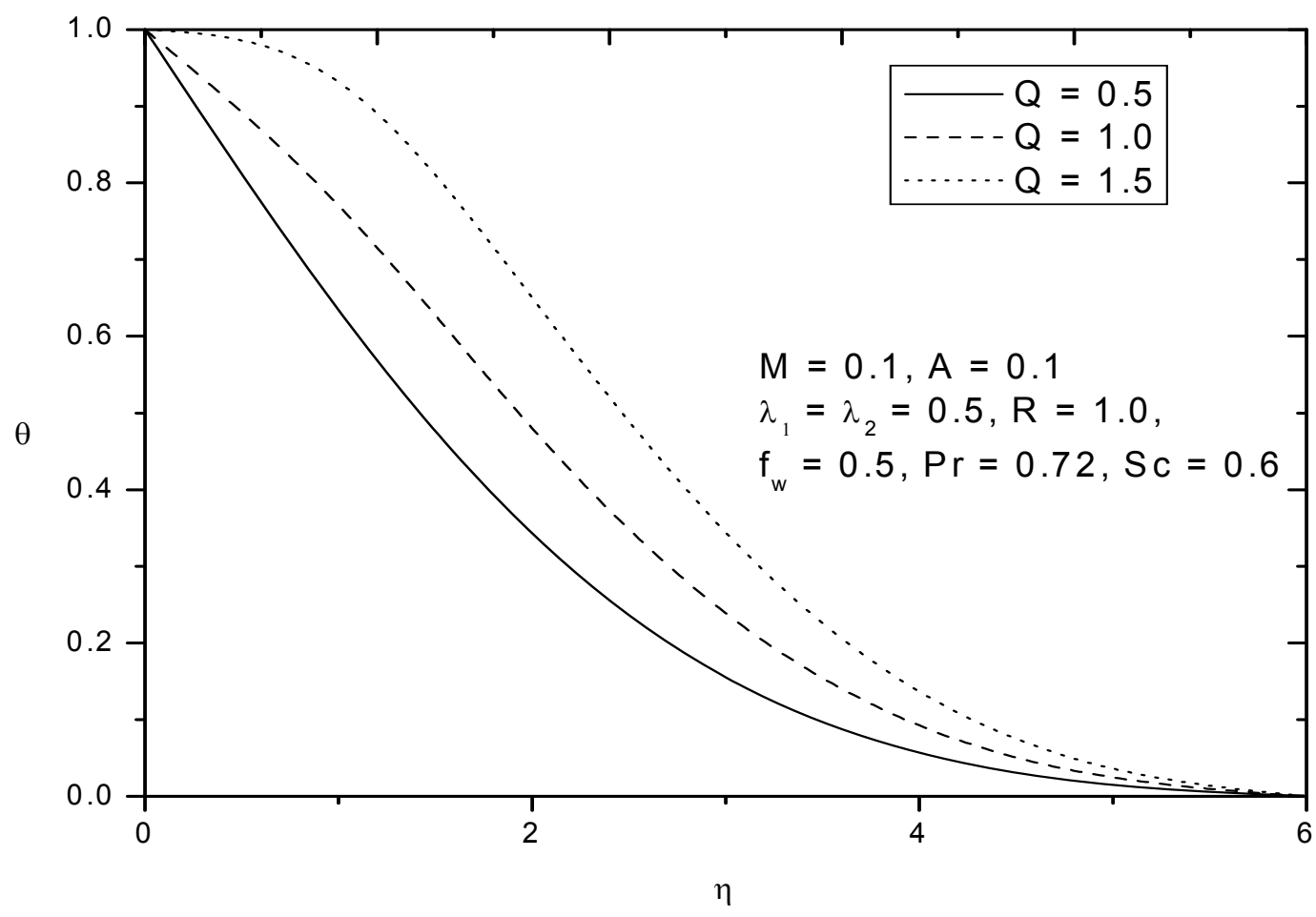

Fig.10. Temperature profiles for different values of $Q$.

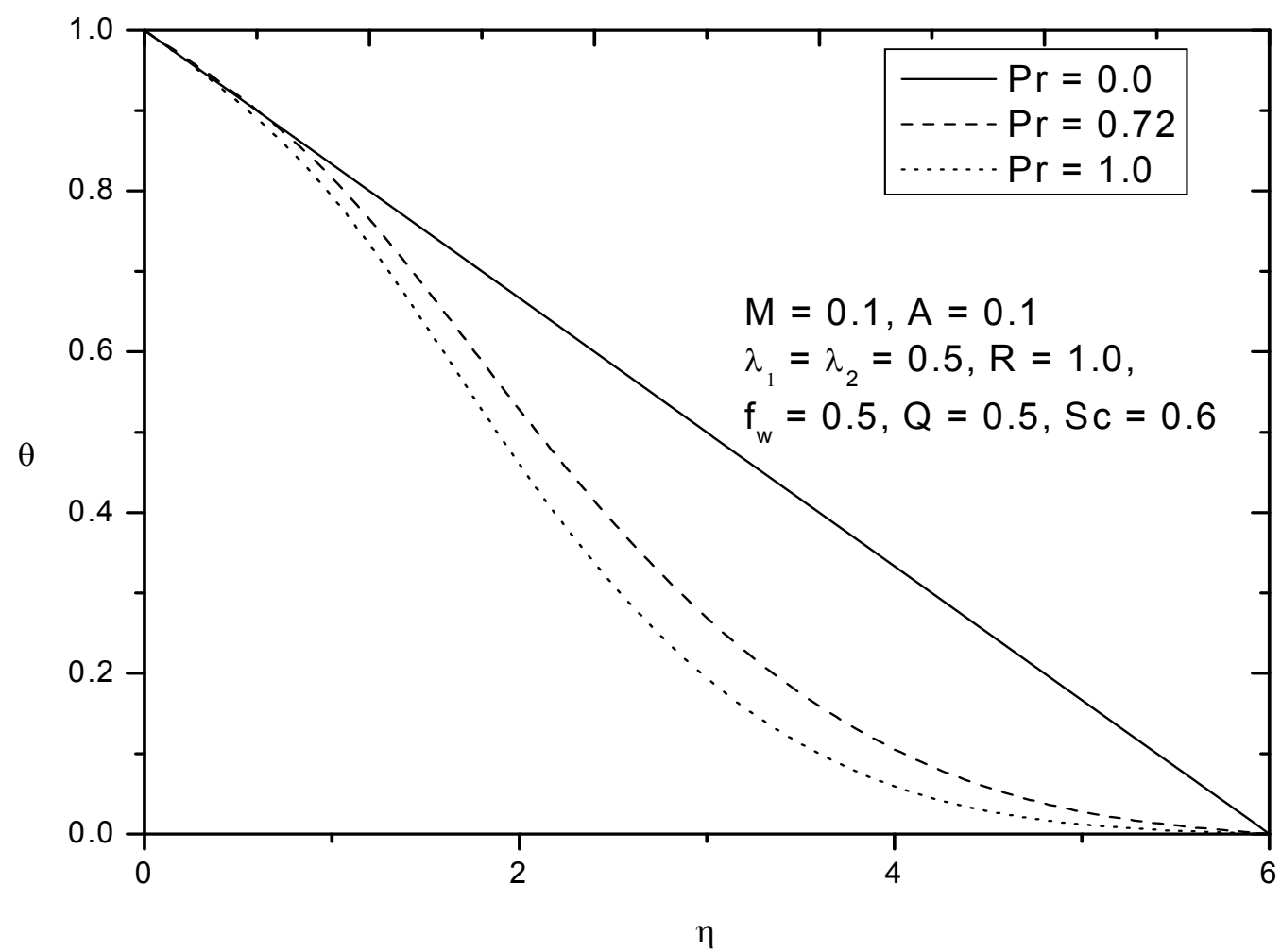

Fig.11. Temperature profiles for different values of Pr. 


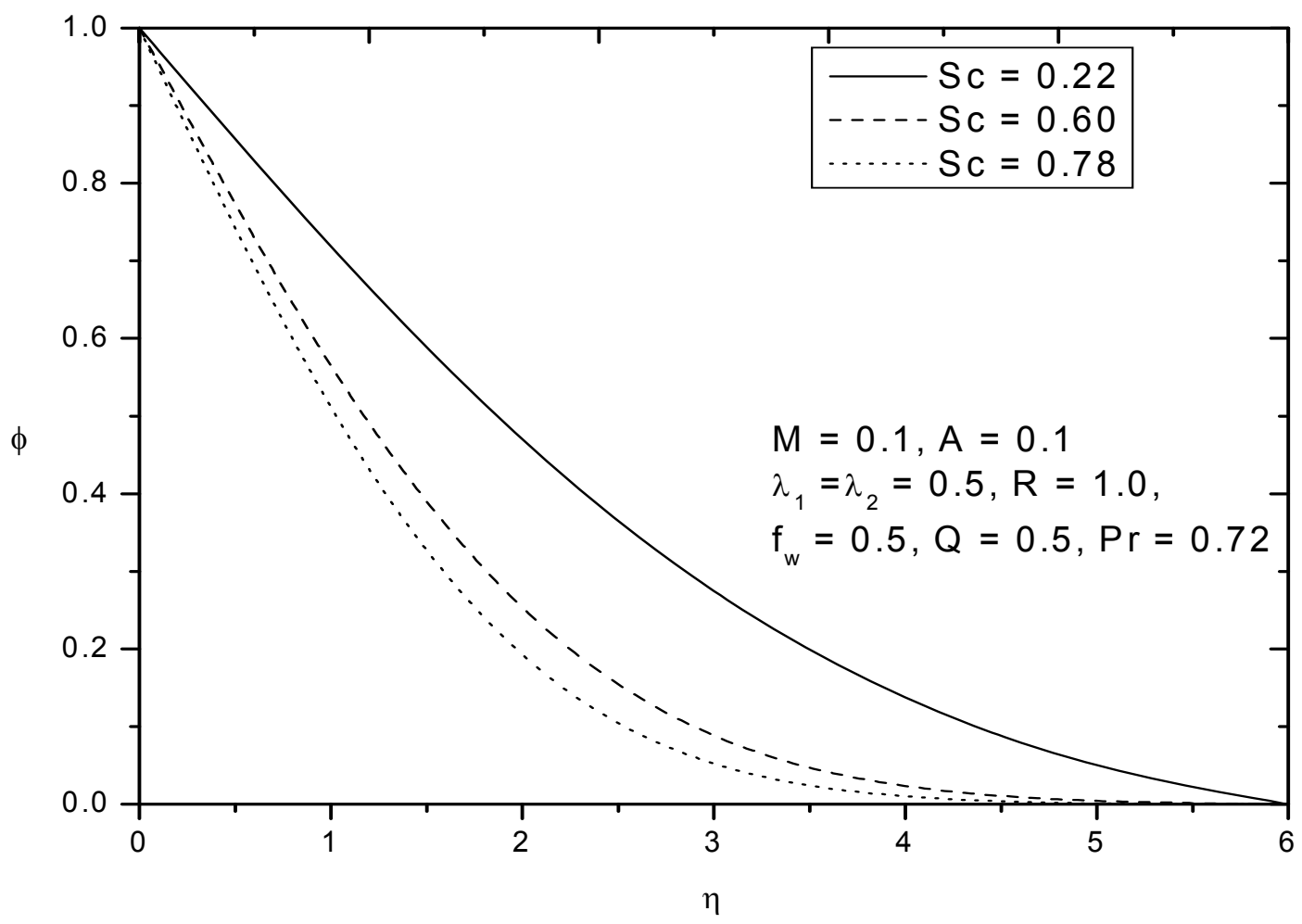

Fig.12. Concentration profiles for different values of Sc.

The effects of various governing parameters on the skin-friction coefficient $C_{f}$, Nusselt number $(\mathrm{Nu})$ and Sherwood number (Sh) are shown in Tab.1. It is observed that the skin-friction increases with an increase in the unsteadiness parameter $A$ or magnetic parameter $M$ or suction parameter $f_{w}$, whereas it decreases with an increase in the mixed convection parameter $\lambda_{l}$ or radiation parameter $R$ or Prandtl number Pr. It is noticed that the Nusselt number increases with an increase in the unsteadiness parameter $A$ or mixed convection parameter $\lambda_{l}$ or radiation parameter $R$ or suction parameter $f_{w}$, whereas it decreases with an increase in the magnetic parameter $M$ or Prandtl number Pr or Schmidt number Sc. It is found that the Sherwood number increases with an increase in the unsteadiness parameter $A$ or mixed convection parameter $\lambda_{1}$ or suction parameter $f_{w}$ or Schmidt number Sc, whereas it decreases with an increase in the magnetic parameter $M$.

Table 1. Numerical values of skin-friction, Nusselt number and Sherwood number $\left(A=0.1, \lambda_{2}=0.2, M=\right.$ $0.1, R=1.0, \operatorname{Pr}=0.72, \mathrm{Sc}=0.60, f_{w}=0.5$ )

\begin{tabular}{|l|l|l|l|l|l|l|l|l|l|}
\hline$A$ & $\lambda_{1}$ & $M$ & $R$ & $\mathrm{Pr}$ & $\mathrm{Sc}$ & $f_{w}$ & $C_{f}$ & $\mathrm{Nu}$ & $\mathrm{Sh}$ \\
\hline 0 & 0.2 & 0.1 & 1.0 & 0.72 & 0.60 & 0.5 & 1.8041 & 0.3269 & -0.2142 \\
\hline 0.2 & 0.2 & 0.1 & 1.0 & 0.72 & 0.60 & 0.5 & 1.8784 & 0.3769 & -0.1204 \\
\hline 0.2 & 0.3 & 0.1 & 1.0 & 0.72 & 0.60 & 0.5 & 1.8523 & 0.3852 & -0.1132 \\
\hline 0.2 & 0.2 & 0.2 & 1.0 & 0.72 & 0.60 & 0.5 & 1.9093 & 0.3784 & -0.1204 \\
\hline 0.2 & 0.2 & 0.1 & 1.5 & 0.72 & 0.60 & 0.5 & 1.8984 & 0.4052 & -0.1204 \\
\hline 0.2 & 0.2 & 0.1 & 1.0 & 1.00 & 0.60 & 0.5 & 1.8784 & 03969 & -0.1204 \\
\hline 0.2 & 0.2 & 0.1 & 1.0 & 0.72 & 0.78 & 0.5 & 1.8784 & 0.3769 & 0.1020 \\
\hline 0.2 & 0.2 & 0.1 & 1.0 & 0.72 & 0.60 & 1.0 & 1.9652 & 0.3856 & 0.1132 \\
\hline
\end{tabular}




\section{Nomenclature}

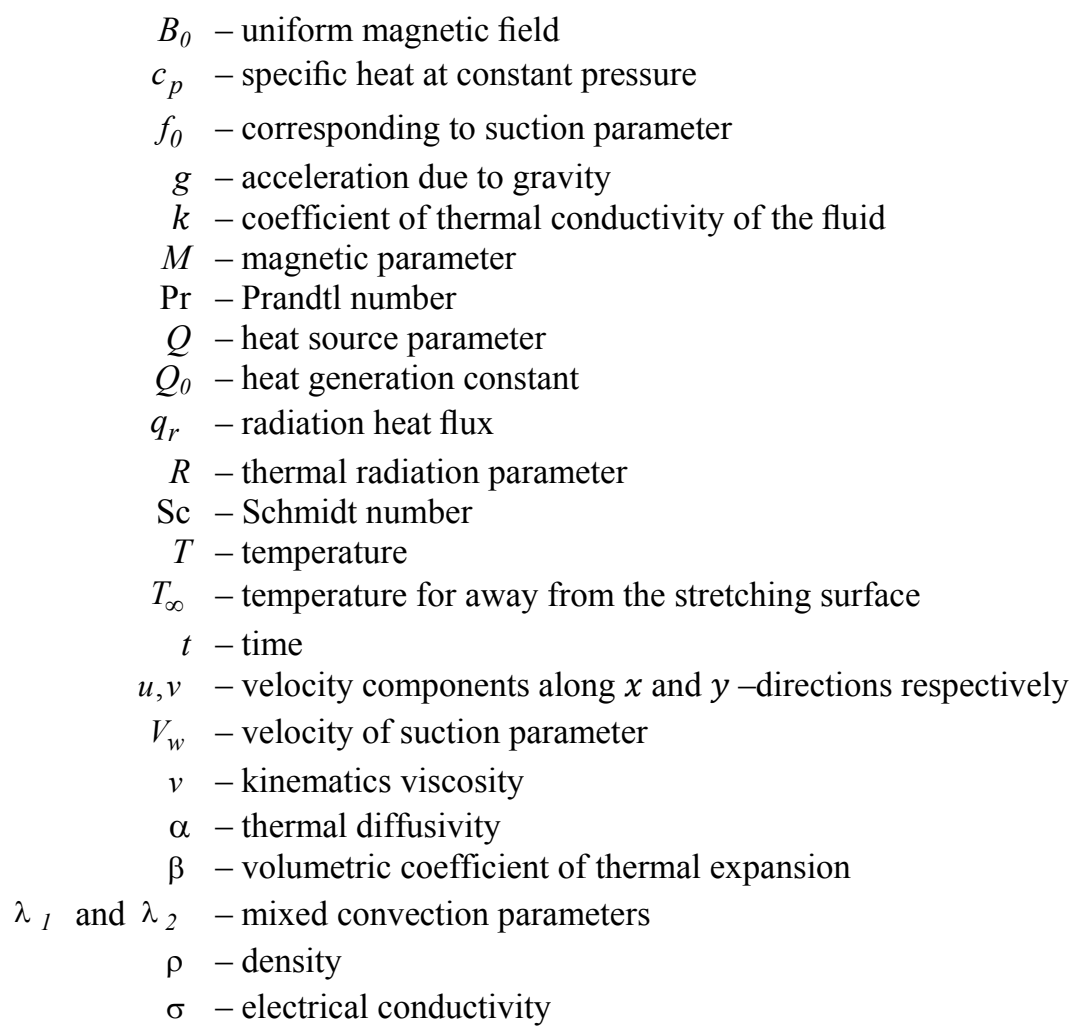

\section{References}

Abramowitz M. and Stegun I.A. (1965): Handbook of Mathematical Functions. - New York: Dover.

Andersson H.I., Aarseth J.B. and Dandapat B.S. (2000): Heat transfer in a liquid film on an unsteady stretching surface - Int. J. Heat Mass Transfer, vol.43, pp.69-74.

Andersson H.I., Aarseth J.B., Braud N. and Dandapat B.S. (1996): Flow of a power law fluid film on an unsteady stretching surface - J. Non-Newtonian Fluid Mech., vol.62, pp.1-8.

Crane L.J. (1970): Flow past a stretching plate. - Journal of Applied Mathematics and Physics (ZAMP), vol.21, pp.590-595.

Dulal P. (2011): Combined effects of non-uniform heat source/sink and thermal radiation on heat transfer over an unsteady stretching permeable surface. - Commun. Nonlinear Sci. Numer Simulat, vol.16, pp.1890-1904.

Grubka L.J. and Bobba K.M. (1985): Heat transfer characteristics of a continuous stretching surface with variable temperature. - ASME J. Heat Transfer, vol.107, pp.248-250.

Hossain M.A. and Takhar H.S. (1996): Radiation effect on mixed convection along a vertical plate with uniform surface temperature. - Int. J. Heat Mass Transfer, vol.31, pp.243-248.

Ishak A., Nazar R. and Pop I. (2009): Heat transfer over an unsteady stretching permeable surface with prescribed wall temperature. - Nonlinear Anal. Real World Appl, vol.10, pp.2909-2913.

Kandasamy R., Wahid A.B., Raj M. and Khamis A.B. (2006): Effects of chemical reaction, heat and mass transfer on boundary layer flow over a porous wedge with heat radiation in the presence of suction or injection. - Theoret. Appl. Mech., vol.33, No.2, pp.123. 
Muhaimin R.K., Hashim I. and Khamis A.B. (2009): On the effect of chemical reaction, heat and mass transfer on nonlinear MHD boundary layer past a porous shrinking sheet with suction. - Theoret. Appl. Mech., vol.36, No.2, pp.101-117.

Nachtsheim P.R. and Swigert P. (1965): Satisfaction of the asymptotic boundary conditions in numerical solution of the system of non-linear equations of boundary layer type. - NASA, TND-3004.

Rajesh V. (2011): Chemical reaction and radiation effects on the transient MHD free convection flow of dissipative fluid past an infinite vertical porous plate with ramped wall temperature. - Chemical Industry and Chemical Engineering Quarterly, vol.17, No.2, pp.189-198.

Rohsenow W.M., Harnett J.P. and Cho Y. I. (1998): Handbook of heat transfer, 3rd edition, New York: McGraw-Hill.

Sakidis B.C. (1961): Boundary-layer behavior on a continuous solid surface: II- The boundary layer on a continuous flat surface. - AIChE Journal, vol.7, pp.221-225.

Seddeek M.A. (2002): Effects of radiation and variable viscosity on a MHD free convection flow past a semi-infinite flat plate with an aligned magnetic field in the case of unsteady flow. - Int. J. Heat Mass Transfer, vol.45, pp.931935.

Sharidan S., Mahmood T. and Pop I. (2006): Similarity solutions for the unsteady boundary layer flow and heat transfer due to a stretching sheet. - Int. J Appl. Mech. Eng., vol.11, pp.647-654.

Takhar H.S., Gorla R.S.R. and Soundalgekar V.M. (1996): Radiation effects on MHD free convection flow of a gas past a semi-infinite vertical plate. - Int. J. N. Meth. Heat Fluid Flow, vol.6, pp.77-83.

Wang C.Y. (1990): Liquid film on an unsteady stretching surface. - Q. Appl. Math., vol.48, pp.601-10.

Wang C.Y. (2009): Analysis of viscous flow due to stretching sheet with surface slip and suction. - Nonlinear Anal. Real World Appl., vol.10, pp.375-380.

Received: February 9, 2013

Revised: August 8, 2013 